\title{
Lifelong learning through digital storytelling in corporate training
}

\section{Aprendizaje permanente basado en el uso de las historias digitales en la formación empresarial}

\author{
Josias Ricardo HACK ${ }^{1}$, Fernando RAMOS ${ }^{2}$, Arnaldo Manuel PINTO SANTOS ${ }^{2}$ \\ y Lucía de FREITAS MOREIRA ${ }^{2}$ \\ ${ }^{1}$ Universidade Federal de Santa Catarina y ${ }^{2}$ Universidade de Aveiro
}

Recibido: Septiembre 2013

Aceptado: Mayo 2014

\begin{abstract}
In this paper we discuss collaborative learning strategies based on the use of digital stories in corporate training and lifelong learning. The text starts with a concise review on theoretical and technical foundations about the use of digital technologies in collaborative strategies in lifelong learning. We will also discuss if the corporate training may be improved by the use of individual audio-visual experience in learning process. Careful planning, scripting and production of audio-visual digital stories can help in the construction of collaborative learning spaces in which adults are in the context of vocational training throughout life. Our analysis concludes emphasizing on the need to experience the routing performance of digital stories in the context of corporate training, following the reference levels mentioned here, so we can have in a future more theoretical and empirical elements for the validation and conceptualization in the use of digital stories in the context of corporate training. Ultimately we believe that lifelong learning can be improved with the use of strategies that promote the production of personal audio-visual for those involved in teaching and learning process in organizational context.
\end{abstract}

Keywords: story telling, corporate education, cooperative learning, lifelong learning, teaching methods, audio visual aids.

\section{Resumen}

En este trabajo se discuten las estrategias de aprendizaje colaborativo basado en el uso de las historias digitales en la formación empresarial y el aprendizaje permanente. El texto comienza con una breve revisión de los fundamentos teóricos y técnicos sobre el uso de las tecnologías digitales en las estrategias de colaboración en el aprendizaje permanente. También vamos a discutir si la formación corporativa se puede mejorar mediante el uso de la experiencia audiovisual individual en el proceso de aprendizaje. También se argumenta que la cuidadosa planificación, programación y producción de historias digitales audiovisuales puede ayudar en la construcción de espacios de aprendizaje colaborativo en el que los adultos se encuentran en el marco de la formación profesional permanente. El análisis concluye con el énfasis en la necesidad de experimentar el rendimiento de enrutamiento de las historias digitales en el contexto de la formación corporativa, siguiendo los niveles de referencia mencionados aquí, así 
que podemos tener en un futuro elementos empíricos para la validación más teórico y como para la conceptualización para el uso de historias digitales en el contexto de la formación corporativa. En definitiva, creemos que el aprendizaje permanente se puede mejorar con el uso de estrategias que promuevan la producción de personal audio-visual para los involucrados en el proceso de enseñanza y aprendizaje en el contexto organizacional.

Palabras Clave: historias digitales, educación corporativa, aprendizaje cooperativo, aprendizaje permanente, métodos de enseñanza, medios audiovisuales.

A storyteller can evoke an emotional connection with the audience and consequently, contribute to the knowledge construction process. After all, as stated by Vygotsky (1998) the uniqueness of a person as historical partner is constituted by its relation to the other in society and the people's way of thinking and acting, depends on social interactions and cultural environment.

In Frazel (2010) opinion, the personal contact between the audience and a storyteller is emotionally charged, with solid eye contact, body language and narration. According to the author, connecting with an audience and bring it into the story can be a deeply rewarding experience for students and teachers.

Moreover, as stated by Barrett (2006), digital stories (hereafter DS) facilitate the convergence of different strategies for learning and if it is identified, it can promote:

- Learner involvement;

- Reflection for deep learning;

- $\quad$ Project-based learning;

- Effective integration of technology in education.

Despite this potential, however, the use of DS is apparently underused in teaching and learning processes within organizations. Therefore, in this article we will discuss collaborative learning strategies based on the use of DS in corporate training and lifelong learning.

In the first section (collaboration in lifelong learning), we propose a concise review of the theoretical and technical usage of digital technologies in collaborative teaching and learning strategies.

In the second section (digital stories in corporative training), we will discuss whether the professional training can be improved with the use of strategies that promote the production of personal videos that are involved in training.

In the third section (the StoryLearn project) we will present the implementation and validation of scenarios for the creation of learning objects (LO) using DS on the StoryLearn project at Portugal Telecom Innovation.

At all times, the main focus will be to discuss the potential of DS in the context of corporate training. 


\section{Collaboration in lifelong learning}

Vygotsky (1998) stated that when a human being ties a knot in the handkerchief as a reminder, it is essentially constructing the process of memorizing by forcing an external object to remind her of something. In other words, it transforms the process of remembering into an outside activity. For the author, the very essence of human memory is that human beings are able to actively remember with the help of signs. It is a general truth that the special character of human behavior is that human beings actively manipulate their relation to the environment and, through the environment; they change their own behavior, subjugating it, to their control.

In Vygotsky's (1998) view, social interaction plays and essential role in the learning process and human development as people acquire new knowledge from their multiple relationships with the environment.

According to Knowles et al (1998), traditionally we have known more about how animals learn than about how children learn, and we know much more about how children learn than about how adults learn. The author states, that scenario was developed like that, because the study of learning was initially supported by experimental psychologists whose canons required the control of variables. Moreover, it is obvious that the conditions under which animals learn are more controllable than those under which children learn. In summary, the fact is that many of the theories of learning derived from the study of learning in animals and children.

Knowles et al (1998) also reminds us that some great teachers of ancient times Confucius and Lao Tse in China, the Hebrew prophets and Jesus in the biblical texts, Aristotle, Socrates and Plato in ancient Greece, and Cicero, Quintilian and Evelid in ancient Rome - were all teachers of adults, not children. Because their experiences were with adults, they developed a very different concept of the teaching and learning process. They considered learning as a process of mental investigation and not as passive reception of broadcast content. So they developed techniques to engage students in the research.

The ancient Chinese and Jews invented what we now call the case-method, in which the leader or a group member of the group described a situation, (often in the form of a parable) and, the group explores its characteristics and possible resolutions. The Greeks invented what we now call the Socratic dialogue, in which the leader or a group member poses a question or dilemma and the group member seeks an answer or solution. The Romans, who were more confrontational, used challenges that forced group members to state positions and defend them.

The andragogical model (adult learning), proposed by Knowles et al (1998), is also based on different assumptions of the pedagogical model (children's learning). According to the author, adults have the need to know why they should learn something before undertaking to learn it. When adults undertake to learn something on their own, they will invest considerable energy in probing into the benefits they will gain from learning and the negative consequences of not learning it. So the first task of the facilitator of learning is to help the learners become aware of the "need to know". A good strategy to increase the level of awareness of the "need to know" is the use of 
real or simulated experiences in which students discover for themselves the differences between where are they now and where would they like to be.

For Knowles et al (1998), adults are motivated to learn things that will help them deal effectively with any situation of real life. Adults are motivated to learn to the extent that they perceive that it will help them perform tasks they confront in their life situations. In addition, they learn new knowledge, skills, values and attitudes most effectively when such issues are presented in a realistic context. The author also explains that even some adults are sensitive to external learning motivators (better jobs, promotions, higher salaries, and so on), the best motivators are internal pressures (the desire for greater job satisfaction, self-esteem, quality of life, and so on).

To sum up, the process of adult learning advocated by Knowles et al (1998) is based on the following:

- Adults are motivated to learn things that meet immediate needs and interests, so these are the appropriate starting points for organizing adult learning activities;

- Adults' orientation to learning is life-centered: therefore the appropriate units for organizing adult learning are life situations, not subjects;

- Experience is the richest resource for adult learning: Therefore the core methodology of adult education should be the analysis of experience;

- Adults have a deep need to be self-directing, so the teacher's role is to engage the students in a process of mutual inquiry rather than transmitting knowledge and then evaluate their conformity;

- Individual differences among people increase with age, therefore adult education should take into account differences in style, time, place and pace of learning.

As we shall see in the next section, using DS as a methodology in the process of adult education can offer an opportunity for the promotion of multiple interactions (collaboration) in the process of knowledge construction. After all, through personal storytelling, trainers and trainees discuss issues centered on their own experiences and meet their immediate needs and interests.

\section{Digital stories in corporative training}

Postman (1989) states that the act of storytelling is closely associated with people's sense of identity. In the same vein, Schank (2005) identifies the stories as one of the component of memory. These are just two endorsement quotes that show the importance of using a methodology that makes use of digital stories for the teaching and learning enterprise.

The starting point of a proposed adult training and work environment that uses DS is the possibility of sharing individual experiences. The main objective is to promote a space of enunciation and narrative about their own experiences, provoking reflections 
on the achievements and failures that each individual has experienced in his life. In other words, the proposed training with the use of DS, participants also recorded small stories of life, illustrated with photos, images, pictures and music that are significant to the storyteller (Miller 2008).

Here, we also want to emphasize the concept of narrative of Savvidou (2010), for whom the idea of storytelling is inherently dialogical, so whenever a story is told, it causes a response. That is, the stories we tell are shaped by the answers of real or potential interlocutors. This idea represents a view of narrative as a dialogue and challenges the notion of history as individual construction.

Savvidou (2010) points out that if we observe the everyday social interactions, we find that the fact of telling a story of personal experience is not presented as a monologue, but as part of an interactional event, a conversation in which stories are mutually constructed by participants. In this process, including the roles of the storyteller and recipient are interchangeable. For the author, within the field of organizational research and communication, studies often include stories of people whose voices typically are not heard, or stories that challenge common standards and organizational structures.

Every corporation has stories that permeate their existence and solidify certain behaviors of their employees. Therefore, in our interpretation, such stories can be told in digital format and used favorably in the context of corporate training, for example, communicating the mission, goals and policies of a corporation. In addition, DS can strengthen values and features that characterize a company and foster teamwork, involving people in strategic actions.

In academic articles with issues related to film and television, it is possible to perceive the existence of multiple processes involved in the production of an audiovisual. With the DS is no different, primarily because its aim is that the video should have some insertion in teaching and learning environments, so it must follow the criteria of the theory of perception. For example, a DS used in the context of adult learning needs several stimuli (narrative, interview, illustration, etc.) to attract the interest of different learners by making clear what are "the key concepts" and how they are related to the learner's everyday needs.

Hack (2010) sets out some important practical steps that can enhance planning and execution of an educational work in audio and video that can be adapted to the production of a DS. The suggested steps are:

- Collection of the information needed to produce an audiovisual and data gathering on the locations where you want to do outdoor shots, as well as to schedule meetings with the people that are invited to the recording studio or interviews, among other information;

- Creation of a resume that will serve as a guide during the recording;

- Setting schedules, environments and permissions for use in locations where images will be taken; 
- Planning shots, prioritizing short scenes that later can be interspersed with other elements such as graphic illustrations of scenes from real life, or animation. If interviews and participations are required they should also be short, lasting one or two minutes;

- Description of the image you want to capture, if possible also creating drawings (storyboard) that can guide the cameraman;

- Defining sound capture, lighting, scenery and other technical aspects;

- Composing images with creativity. The aim is to think of different camera angles and framings (long distance, middle distance and close-ups). It is also important to plan more than one option for the same content, for example, vary from the image of the contents presenters and from the audio of the speakers, including illustrative pictures;

- Creation of scenarios, rental costumes and makeup design, if such things were essential to the final quality of the audiovisual product;

- Edit and finalize the movie. At this stage, the suggestion is to avoid a very long movie, even if you have a lot of raw footage to edit on your own. In some cases the time limit may be impractical due to the features of contents and to solve this issue is recommended to split the material into smaller parts, like chapters.

It is interesting to note that the above suggestions already compose a sort of road map that shows directions on the way to go during the planning of an audiovisual work as a DS. According to Hack (2010), the above recommendations can maximize the time spent to produce and edit an audiovisual, as a well-developed plan helps prevent problems that may adversely affect work accomplishment.

It is also important to note that with respect to the use of DS in the context of corporate training, Savvidou (2010) highlights the importance of the concept of "dialogue" in the narrative. According to the author, although little attention is given to the concept of narrative as a dialogue in educational contexts, this is a rich front of research in organizational and communication research. In this area, storytelling is represented as a shared social practice, through which explicit and tacit knowledge can be transmitted as well as acquired identities.

For Porter (2004), there is much to consider in building a DS, because there are infinite approaches, depending on the purpose and the public we want to achieve. The author draws attention to the fact that if it is desired to use this style of narrative, there is a need to be aware of some basic elements. According to Porter (2004):

- A DS lead others to experience their story. In other words, each DS has a personal perspective and needs to be narrated by the author. The aim is to approach the reality experienced by the storyteller to the present viewer's experience;

- A DS always bring a lesson to be learned. One of the most unique features of the methodologies that use DS is the expectation that each story express 
a personal meaning or insight about how a particular event or situation has touched the life of the author and perhaps it can touch the lives of people who watch the video;

- A DS develop a creative tension. A good story creates intrigue or tension around a situation that is posed at the beginning of the story and resolved at the end. This strategy involves us with the DS and can even lead to collaboration;

- A good story has a destination - a point to make - and seeks the shortest path to its destination. You need to know how to dose the words and images;

- Good stories use vivid details to reveal feelings and information instead of just saying something;

- A good story incorporates technology in artful ways, demonstrating craftsmanship in communicating with images, sound, voice, color, white space, animations, design, transitions, and special effects.

Then we realize that the potential of the methodology as an opportunity to promote multiple interactions (collaboration) in the process of knowledge construction in corporate environments (Frazel 2010; Kearney 2011). For example, in certain corporate training proposals, it will be able to introduce contents and thematics produced as the features of a DS, to provoke interest in adult learners to share their own stories, also using the same technique. Thus, both trainers/teachers and learners/students would interact in a collaborative learning experience through the use of small stories in a digital two-way street.

As we have seen here, the comments seem to point us that the careful planning, scripting and production of DS can help in the construction of collaborative learning spaces in which adults are in the context of vocational training throughout life. However, when we take such paths and benefitiate from them, we remember an important piece of advice given by authors who have experience in the area (Frazel 2010; Hack 2010; Miller 2008; Porter 2004): to take care of the copyright matters when using images and sounds. Whenever we make audio recordings and video footage with other people, indoors or outdoors, we need the authorization for the use of the materials that will be originated, even if the future use has no commercial purposes.

Finally, we emphasize that we believe that there is a latent need for the scientific community to give attention to research on the question of using DS in corporate training. Even we managed to see that there are several possibilities and they should cover aspects related to arguments such as epistemological, methodological, technological, operational, ethical, legal, etc. As an illustration example, we mentioned that our current project aims to operationalize and validate a methodology for use of DS in the context of vocational training through critical reflection and empirical experimentation. The research is a partnership between the University of Aveiro (www.ua.pt) and Portugal Telecom Innovation (www.ptinovacao.pt). The aim of the 
project is to develop scripts for DS, produce them and then test the effectiveness and efficiency of use of such video in training environments.

\section{The StoryLearn project}

The StoryLearn project (at Portugal Telecom Innovation) was designed for the study, design, implementation and validation of scenarios for the creation of learning objects (LO) using DS as the communication strategy, with the aim of fully completing the eLearning services offer, in terms of both content and function. These eLearning services are, currently, deployed by the FORMARE LMS platform, specifically by the new LO management system known as COLOR (Collaborative Learning Objects Repository).

Given this general background, a number of supplementary objectives were identified for the StoryLearn project, on the basis of recent scientific and technical advances. These are:

- The systemisation and validation of a methodology for using DS in a professional training context.

- The creation and integration of scenarios and technological conceptual models, at the level of learning, communication and the integration of services in eLearning environments and LO portals.

- The creation of LO using DS as a communications and training strategy.

- The identification of the advantages that DS might offer to Portugal Telecom Innovation for its internal training programmes.

\section{The importance of LO technology and the COLOR system}

The concurrence of the need for just-in-time training for self-learning scenarios with semantic information search mechanisms and the imperative requirement to recycle pedagogical material underpinned the drive to develop a learning objects system (PoLO - LO Portal).

This PoLO system supported the operation of knowledge integration and management techniques and methodologies for the construction of learning objects that were able to serve as a base for satisfying the ever-present demand for pedagogical material.

One of the main problems this project aimed to resolve was that of the need to integrate data from different learning management systems (LMS and LCMS) and reuse these in the process of developing and managing learning objects.

PoLO consisted of the development of a prototype designed to apply semantic web, artificial intelligence and Web 2.0 techniques in a learning organisation environment (supported by LMS FORMARE - the learning managment system developed by Portugal Telecom Innovation). 
This prototype, together with the trends seen in Web 2.0, served as a basis for moving on to a second research phase, which consisted of developing this system line into a collaborative logic (the COLOR - Collaborative Learning Objects Repository project).

COLOR (figure 1) is, thus, a collaborative LO system, which is organised into three broad areas:

- A1: Study, creation and interaction with the LO

- A2: LO management and system management

- A3: Search and recommendations on information and training.

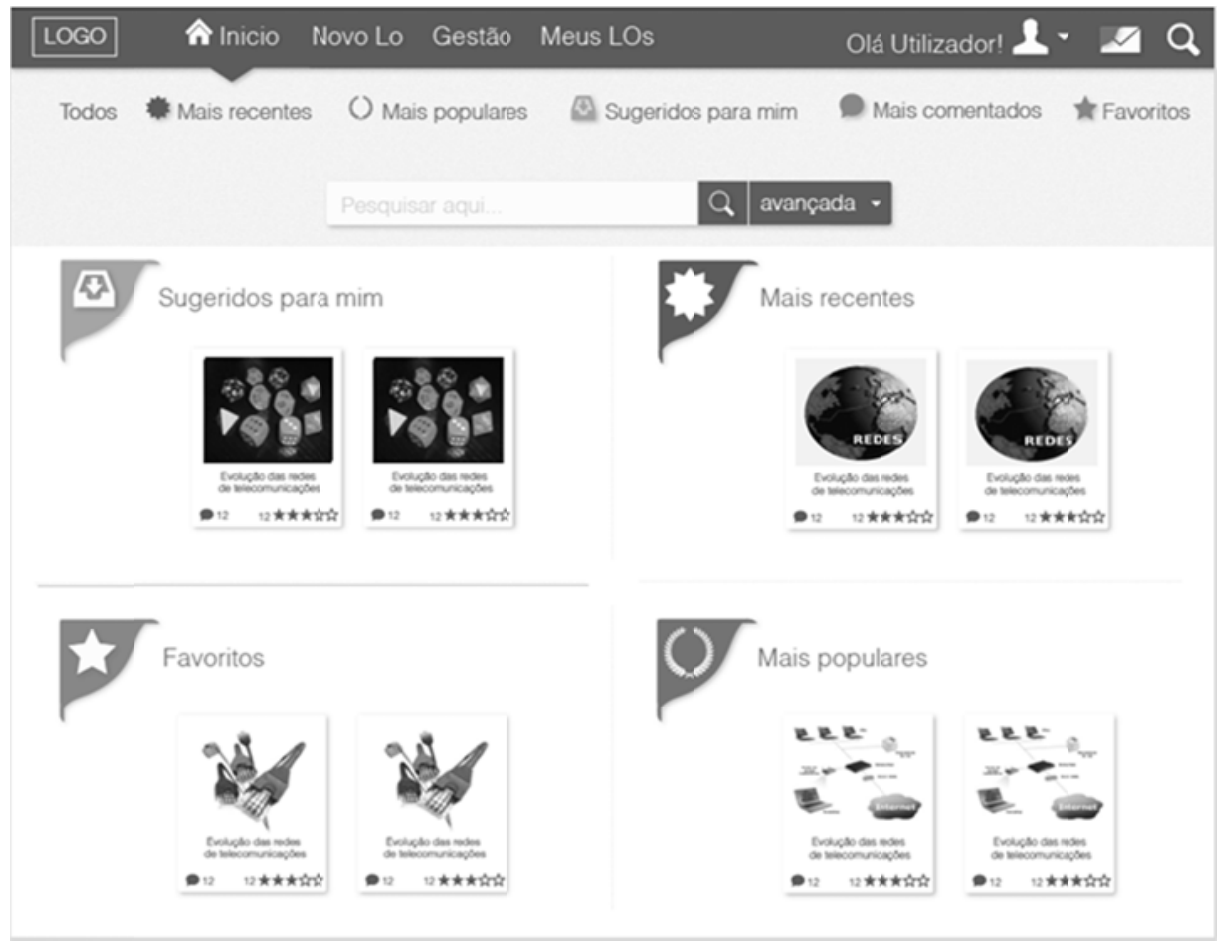

Figure 1: User interface in the COLOR system

COLOR's main functions can be described through a set of scenarios:

- Scenario 1: Study, creation and interaction with the LO

- Scenario 2: LO management and system management

- Scenario 3: Information search 
The main information flows in the COLOR system take place between agents of varying types and in relation to a body of information and training that is structurally organised into learning objects.

These learning objects may be described by type (script, video, image and multimedia) and pedagogy (quiz, animation, multimedia content, eBook, video, DS, case study, simulation, tutorial).

The aim is for the results of the StoryLearn project to be directly integrated into the COLOR system as learning object paths, in the form of learning objects, which may be organised in the form of atomic information models or of pedagogical proximity models.

The narratives that support the project results should be prepared in such a way as to be able to operate independently within these two models.

The stories produced by the StoryLearn project will be validated in a real COLOR system learning environment, by Portugal Telecom Innovation staff. The trainees will focus on topics related to their products and services and the stories will operate as a support tool for professional training.

\section{Implementation of the storylearn project}

To meet the project's objectives using the LO management system described, we had to design an implementation strategy and technical approach that was suitable for adult training.

On the assumption that:

- As most people like to listen to and hear stories, the use of DS, as a social storytelling practice that involves the use of digital cameras, non-linear text and image editing tools and computers to create multimedia content, Portugal Telecom Innovation needs to look at this approach for its training contexts, and that

- In the educational and training context, DS is mainly used, according to Jonassen and Hernandez-Serrano (2002), to: exemplify certain concepts or principles, research cases or problems and offer access to certain forms of advice that might help learners learn how to solve problems.

The technical work undertaken by the StoryLearn project was organised in the following way:

- The carrying out of an in-depth state-of-the-art study of the storytelling technique, using real case studies, with a specific focus on business market environments.

- The validation of the concepts determining the integration of this communicative technique in the LO to be integrated into the Color environment. 
- The selection of scenarios based on the principles underlying the storytelling technique, for two specific cases of transversal technological training.

- The construction of the narratives in multimedia format, on the basis of the context/story to be told for each LO.

- The technological adaption of the multimedia resources produced for each scenario.

- The testing and validation of the prototypes in a real training situation.

- The development and dissemination of the functional prototypes in a multimedia environment, integrated in Color and distributed in a real professional training scenario.

Scenario 1 involved a technological content for the area of computer networks entitled "Introduction to IPv6". This is a face-to-face course that is regularly run at Portugal Telecom Innovation.

Multimedia narratives were constructed for this scenario on the basis of the context/story to be told for each LO and the necessary technological adaptations were made to the multimedia resources produced.

After studying the original scientific content, the context, target public and set of narrative-based questions were all identified for the filmed interview that was used to prepare nine separate LO-format videos, called VLO (Video Learning Object):

1. Why do we need more IP addresses?

2. When did IPv4 end?

3. Are IPv4 and IPv6 compatible?

4. Why do away with IPv4?

5. Why do we need to change to IPv6?

6. What factors underlie the change from IPv4 to IPv6?

7. Is IPv6 good enough?

8. Why does IPv6 have 128 bits?

9. How did IPv6 come about?

The study also made it possible to broaden the discussion and understanding of production and filming issues, particularly at the technological and pedagogical levels. This, in turn, led to a number of recommendations, namely:

- For each VLO to be independent and, therefore reusable, the story must be self-contained, that is, it must exist as an independent unit and not depend on other VLO. 
- Each story should be told by a Portugal Telecom Innovation person with the right credentials in the VLO's subject area.

- The story should result from the narrator's direct experience and this fact should be clear to the trainee taking into account the narrator's activity and responsibilities within the company.

- Technically, the audio and video should both be of good quality.

- The inclusion of infographics helps develop cognitive reinforcement and highlights the dramatic nature of the various parts of the story.

- The self-assessment component at the end of each VLO helps consolidate learning and makes the trainee more aware of the relevance and extent of the knowledge that has been acquired.

The making of each VLO involved a set of filming-related technical tasks:

- Aesthetic considerations regarding framing and a balanced use of different types of backdrop.

- Using backdrops and scenarios that make it easy to insert infographics.

- Insertion of informative content into the videos: initial question, oracle, credits and subtitles.

- Insertion of animated infographics into the audiovisual narrative (created using public domain icons adapted to communication of the topic).

Also part of the StoryLearn project is the ongoing production and filming of other training topics relevant to Portugal Telecom Innovation. The project, which ends in September 2012, also includes a training effectiveness assessment phase based on questionnaires and interviews with trainees who have been using the VLO in real training contexts.

\section{Conclusions}

Any citizen, who has access to adequate technologies and techniques, can tell his own story digitally. As we try to show here, in the context of lifelong learning and corporate training, this possibility resizes the characteristics of audio-visual production that once was exclusive to highly specialized teams. What we mean is that the possibility was created to give voice and visibility to digital stories produced by those on both ends of the teaching and learning: the student/learner and his teacher/trainer.

Our text aimed to defend the use of DS as a strategy for teaching and learning in the context of corporate training, having the necessary characteristics to provide opportunities for collaboration, appreciation and respect to the multiple social and cultural interactions. In our comprehension a DS strategy can be used as a lever to individual and collective movements that generally characterize the process of teaching and learning in organizations. 
Of course we know that new skills are required for actors that use a DS based training strategy. However, this issue would require a new article. Therefore, our analysis concludes with the emphasis on the need to experience the routing performance of DS in the context of corporate training, following the reference levels mentioned here, so we can have in a future more theoretical and empirical elements for the validation and for the conceptualization for the use of DS in the context of corporate training. Including we deploy the results of the DS study at Portugal Telecom Innovation and the VLO themselves, tell us that:

- DS sets up a creative tension; a good story provokes situation-based curiosity or tension at the beginning of the story, which then needs to be resolved.

- $\quad$ DS should be economical: a good story has a destination or objective and seeks the shortest path to achieving this.

- DS shows, and does not just tell, a story: good stories carry a richness of lived detail that reveal emotions and feelings that go beyond mere information on the topic.

- DS is a craft: a good story incorporates the technology in an intelligent way, displaying its ability to communicate with images, sound, voice, colour, white space, animations, designs, transitions and special effects.

One of the questions that this project sought to answer concerns the potential of the DS methodology to boost the performance and motivation of trainees taking part in rapid learning type training. On the basis of the results of the StoryLearn project, we believe that the use of DS in training:

- Shows great potential for business training.

- Offers an emotionally relevant contact with a specialist from within the organisation.

- Helps reduce the costs of developing and updating learning contents/materials.

- Has the potential to be an excellent communication and training strategy for rapid learning and mobile learning contexts, given that it allows training content to be deployed more quickly than by other means. It also stimulates a granularity of contents that is appropriate for those situations in which training needs are specific and contents are accessed via mobile technology.

In summary, we believe that lifelong learning can be improved with the use of strategies that promote the production of personal videos for those involved in training. In other words, we understand that digital stories can enhance collaborative learning in adult vocational training. After all, these strategies may promote personal experiences of socialization spaces that will serve as an illustration of how to deal with real-life situations. 


\section{References}

BARRETT, H. (2006). Researching and evaluating digital storytelling as a deep learning tool. In Crawford, C. et al. (Eds.). Proceedings of Society for Information Technology and Teacher Education International. Chesapeake, VA: AACE. pp. 647-654.

FRAZEL, M. (2010). Digital Storytelling: guide for educators. Washington, DC: ISTE.

HACK, J. R. (2010). Linguagem virtual e audiovisual na EAD. In Tafner, E. et al. Produção de materiais auto instrutivos para EAD. Indaial: ASSELVI. pp. 59-87.

JONASSEN, D. H.; HERNANDEZ-SERRANO, J. (2002). Case-based reasoning and instructional design using stories to support problem solving. Educational Technology Research and Development, 50(2), pp.65-77.

KNOWLES, M. S.; HOLTON, E. F., SWANSON, R. A. (1998). The adult learner: the definitive classic in Adult Education and Human Resource Development. Woburn: Butterworth-Heinemann.

KEARNEY, M. (2011). A learning design for student-generated digital storytelling. Learning, Media and Technology. 36(2), pp. 169-188.

MILLER, C. H. (2008). Digital Storytelling: a creator's guide to interactive entertainment. Burlington: Focal Press.

PORTER, B. (2004). DigiTales: the art of telling digital stories. Sedalia: Porter.

POSTMAN, N. (1989). Learning by story. The Atlantic, 264(6), pp. 119-124.

SAVVIDOU, C. (2010). Storytelling as dialogue: how teachers construct professional knowledge. Teachers and Teaching. 16(6), pp. 649-664.

SCHANK, R. C. (2005). Lessons in learning, e-learning, and training: Perspectives and guidance for the enlightened trainer. San Francisco, CA: Pfeiffer.

VYGOTSKY, L. S. et al. (1988). Linguagem, desenvolvimento e aprendizagem. São Paulo: Ícone. 


\section{Correspondencia con los autores}

Josias Ricardo HACK

Universidade de Santa Catarina

Departamento de Artes e Libras - Prédio B do CCE

88.040-900 Florianópolis - SC - Brazil

e-mail: j.r.hack@ufsc.br

Teléfono: +55 4837216543

Fernando RAMOS

University of Aveiro

Dept of Communication and Art

3810-193 Aveiro - Portugal

e-mail: fernando.ramos@ua.pt

Teléfono: +351234370200

Arnaldo Manuel PINTO SANTOS

Portugal Telecom Inovação

Rua Eng. José Ferreira Pinto Basto

3810-106 Aveiro - Portugal

e-mail: arnaldo@telecom.pt

Teléfono: +351234 403200

Lucía de FREITAS MOREIRA

Portugal Telecom Inovação

Rua Eng. José Ferreira Pinto Basto 3810-106 Aveiro - Portugal

e-mail: lucia-f-moreira@telecom.pt

Teléfono: +351234370200 